\title{
Pre-installation challenges: classifying barriers to the introduction of smart home technology
}

\author{
Luis Carlos Rubino de Oliveira \\ Design School \\ Loughborough University \\ Loughborough, UK \\ L.Oliveira@lboro.ac.uk \\ Andrew May \\ Design School \\ Loughborough University \\ Loughborough, UK \\ A.J.May@lboro.ac.uk \\ Val Mitchell \\ Design School \\ Loughborough University \\ Loughborough, UK \\ V.A.Mitchell@lboro.ac.uk
}

\author{
Mike Coleman \\ School of Civil and Building Engineering \\ Loughborough University \\ Loughborough, UK \\ M.J.Coleman@lboro.ac.uk
}

\author{
Tom Kane \\ School of Civil and Building Engineering \\ Loughborough University \\ Loughborough, UK \\ T.Kane@lboro.ac.uk \\ Steven Firth \\ School of Civil and Building Engineering \\ Loughborough University \\ Loughborough, UK \\ S.K.Firth@lboro.ac.uk
}

\begin{abstract}
Increasing technological developments indicate potential for a variety of improvements in the domestic environment. As part of an interdisciplinary research project, this study interviewed households prior to the installation of smart home technologies (SHTs) in order to identify critical issues at the pre-installation phase. Semi-structured interviews took place in 16 houses before the installation of SHTs, when a range of smart sensors and controls were presented to households for the first time. At this stage, they started to make key decisions about which devices to use, where to install, and how to position them. Participants mentioned diverse issues surrounding the introduction of SHTs. To guide the qualitative analysis, an organizing framework for research on smart homes and their users was used. This paper indicates that, even though participants appreciate the functional aspects of SHTs and the possibilities of a better living, their concerns related to technology (hardware \& software), design (acceptability \& usability) and spaces (home as complex places) are numerous. These results complement the existing literature (which focuses more on the use phase) with the perceived enablers and barriers prior to the installation of SHTs.
\end{abstract}

Keywords—smart home technology; retrofit; domestic sector; energy saving;

This work is funded by the Engineering and Physical Sciences Research Council (EPSRC) under the Transforming Energy Demand in Buildings through Digital Innovation (BuildTEDDI) funding programme. For more information see: www.epsrc.ac.uk and www.refitsmarthomes.org

\section{INTRODUCTION}

Human activities impose significant challenges to sustainability, and governments try to reach agreements on carbon emissions in an attempt to combat climate change [27]. Countries often have programs targeting energy conservation in diverse fields such as greener generation and efficiency, often with limited success [31]. The UK government expects, by 2050 , an $80 \%$ reduction in carbon dioxide emissions in comparison to 1990 levels [18]. The housing sector accounts for more than one third of the total energy use, and space heating is the largest energy end use in homes [18]. Therefore, efforts towards reducing gas and electricity consumption within the domestic sector will have an important effect on overall consumption.

There are three general routes for reducing rates of energyconsumption in the domestic sector [57]. These comprise of (i) replace the existing stock or refurbish current homes to achieve low-energy standards, (ii) use only low energy appliances and other equipment, and (iii) promote energy saving behaviours among occupants. Previous research indicates a potential for reducing domestic energy use merely through behaviour change. For example, even when living in low energy houses, inhabitants can behave in a non-efficient way [14, 32]. However, in order to comply with building standard regulations and government recommendations, existing houses will require diverse physical improvements. Those involve heat efficiency through improved insulation and glazing, electrical 
efficiency in lighting and appliances, and building-level decarbonized heating [39].

At present, there is debate around the proposition of large scale clearance and new constructions to accelerate the replacement of inefficient stock with new, improved homes [7]. However, studies indicate that refurbishment of the existing housing stock offers clear advantages in time, cost, and can still reduce significantly energy use in buildings [46]. Energy efficient renovations of existing buildings, usually referred to as 'retrofit', can work as an alternative to reducing a buildings' footprint. Even older, poorly insulated and hard-to-treatbuildings "can be retrofitted to achieve high energy efficiency standards" [13].

A recent research project proposes the 'power law of engagement' [52] to guide users through seven steps towards the 'master' level, i.e. an energy efficiency expert. The authors state that it is important to find the key barriers and drivers "to get disengaged households retrofitting their properties" [52]. Previous research lists some of the barriers that deter people from performing domestic improvements, which limit the implementation of energy efficiency measures [41]. The most frequent explanations mentioned were their own values as barriers (i.e. what they deem as important), financial cost, the professionalism of the building industry (e.g. poorly skilled, unreliable or costly), lack of time or property features (e.g. size, shape characteristics of the property), among others. Their results show that a range of social and emotional barriers can "cause inertia or even halt projects for many years" [41]. Wilson et al. [53] identified four key variables influencing efficiency renovations: (i) attributes such as upfront costs and payback periods; (ii) decisions about expectations on savings or reliability of contractors; (iii) characteristics of the decision makers (age, education, attitudes, household size and composition); and (iv) contexts like home tenure and physical characteristics. One comprehensive literature review [54] indicated dozens of themes influencing homeowners' renovation decisions, as highlighted by applied behavioural research. Results showed a range of personal and contextual variables which may explain why "homeowners remain stubbornly resistant to improving their homes' energy efficiency" [54].

One recent policy initiative to attempt to reduce carbon emissions in the UK is the 'Green Deal' [19]. This scheme tries to reduce barriers by eliminating the initial financial costs of energy saving retrofits and minimizing uncertainties on contractor reliability. Refurbishment of properties will be supported by the scheme via a loan, and the debt will be added to (hopefully reduced) gas and electricity bills. Studies show that households are often uncertain about future financial benefits [45], predicted savings can be overestimated, and hard-to-treat dwellings and residences in fuel poverty are unlikely to be included [8].

A number of studies have evaluated the role of technology to bring about sustainability. The potential of technological interventions has gained increased attention in the past decades in fields with diverse titles such as Sustainable Interaction Design [6], Environmental Human-Computer Interaction (HCI) [33], Sustainable HCI [24, 40, 49] or Information and
Communication Technologies for Sustainability (ICT4S) [38]. However, there is demand for increased research in the area, especially regarding success evaluation $[40,49,50]$.

A large body of research investigates the use of smart meter data as a way of providing feedback of energy use and motivating savings $[1,15,16,59]$. Previous research indicated that feedback should be given frequently and over a long period of time, providing appliance-level breakdown, having a clear and appealing presentation, and be computer-based [29]. However, the effectiveness of smart meter data might be sometimes over-estimated [10,11]. Savings can be modest [29] or non-existent: a study with randomly selected households demonstrated that a display with real-time information had no effect on electricity consumption [43]. Feedback technologies often fade into the background with time, and savings can be compromised by the rebound effect [56]. People sometimes compensate savings increasing expenditure on the same or other energy intense activities, therefore part of the efficiency provided by the behaviour change or technological improvement is offset by increased consumption [5, 34].

Smart home technologies (SHTs) attempt to expand on the provision of feedback about the consumption of resources by providing building occupants with advanced monitoring and control capabilities [2]. A growing body of research explores the potential of SHTs [22], but frequently focuses on the diverse possibilities offered by the technological developments. It has been observed that the consumers' needs are sometimes overlooked in often technology-driven projects [35]. Content analysis of marketing materials indicates that the smart home industry portrays users as being rational decision makers who want to save energy, money and time [36]. Users roles are limited to 'taking' the technology once it is installed in their homes, and user involvement in co-design, experimentation or adaptation is not mentioned. It appears that both industry and academia dedicate more efforts into the technological aspects of smart homes. The disciplinary areas of articles selected for a systematic literature review "was overwhelmingly based in the engineering and technical sciences (67\% of all articles) with medical and health sciences $(20 \%)$ and social sciences $(13 \%)$ much less common" [36]. Previous research suggested technical, social and pragmatic challenges [25] which should be addressed to increase the chances of wider adoption of SHTs. Research with users of smart homes illustrated issues involving inflexibility and poor manageability of these systems, indicating limitations to broader acceptance [9].

A systematic review of the current state of research identified a gap in the literature regarding the users and how they might use SHTs [55]. Likewise, an earlier research study suggested the need for flexibility and modifications in SHTs to fit the improvisations and breakdowns observed in domestic routines [17]: "Smart Home technology looks set to become a feature of people's lives, whether it is wanted or not". But it is important to identify what people value in their home environment [35]. As highlighted by a previous review [37], there is a tendency to focus on optimising efficiency, as if technology could alone address the issue of energy consumption. The success of using technology to promote sustainability in the home depends not only on the advancing technological development towards enhanced functionalities 
and energy management, but also "the needs and demands of households in the complex places that are homes" [55].

Research on SHT as ICT4S is especially important given the rollout of smart meters scheduled nationally in the UK and the possibility of integrating it with SHT currently in the marketplace. The government promised to introduce smart meters in every dwelling by 2019 [20] and several additional systems can be purchased off-the-shelf [36] to provide a wide range of potential benefits such as safety, leisure, e-health and home energy management [12]. DECC explains that the proposed smart meters can stablish wireless 'home area networks' which will allow consumers to pair devices such as displays, controls and smart appliances [21]. It indicates that homes are soon becoming more connected and more capable. With increasing technological developments, the affordances brought about from the smart meter rollout and the opportunity for the final user to buy SHT commercially available themselves, there is the need to understand the range of issues to do with the installation of this technology. Therefore this study investigated people's perceptions prior to the installation of SHTs in order to identify enablers and barriers related to the introduction of a range of smart sensors and controls, when they were presented to households for the first time.

\section{THE REFIT PROJECT}

The REFIT project is a multidisciplinary research investigating the use of SHTs in UK homes. The project aims to improve knowledge and understanding about how smart meter and home data can be used to provide personalised retrofit advice to homeowners and how consumers accept, adapt and use SHTs. The premise is that additional information on aspects such as room temperatures, occupancy sensing and gas consumption could potentially help households' retrofitting decision making process. In other words, using smart home data streams could help "to improve our understanding of actual building performance" and consequently "better advice can be given to the householder on the energy savings available from retrofitting" [28]. The ultimate goals comprise improving energy efficiency and adoption of on-site renewable technology options for UK homes.

Final outcomes of this research project will involve different approaches for providing retrofit advice, based on persuasive ICT-enabled decision support systems derived from the Smart Home data. Through the interaction with the system householders will obtain the advice for long-term behaviour change and for well-informed retrofit purchasing decisions.

The REFIT project is conducting a 2.5 year field study and has deployed SMTs in a sample of 20 UK homes. The equipment was installed in two main phases. During a first round of home visits in 2012-13 a number of gas, electricity and temperature monitors were installed. These sensors collected baseline data and provided information for studies on thermal performance modelling [23] and power disaggregation [26], among others. Households were not given access to the data at this point.
The second phase of this research involved the final installation of the SHTs into the participants' homes. Smart sensors and controls were installed and access to the online services given to participants. RWE Smarthome ${ }^{\text {TM }}$ devices ${ }^{1}$ were fitted to manage the heating system output, allow zonal thermal control and provide home security features. The devices include:

- One central controller that communicates with the other RWE devices

- Nine radiator thermostats with remote or local control of temperature. This device is also a temperature and air humidity sensor.

- Three room thermostats to control radiators in a particular room or zone

- Six indoor and one indoor motion detectors with integrated brightness sensor

- Door and window contact sensors to record opening and closing events

- One smoke detector and alarm

- Two wall-mounted transmitters working as physical switches to trigger actions

- One remote control providing 8 buttons which can be configured to control devices in the RWE system.

Additional devices include Z-Wave Vera3 ${ }^{\mathrm{TM}}$ controllers $^{2}$ and Current Cost units ${ }^{3}$ to monitor electricity consumption, and $\mathrm{Z}$-Wave smart plugs to give remote and automated control over selected appliances. British Gas Hive Active Heating system ${ }^{4}$ was also offered to households as a way to control their boiler remotely. Those who wanted and had a compatible boiler had it installed during a subsequent phase.

\section{STUDY DESIGN}

The demand for better understanding of SHTs from a user's perspective motivated the design of this study. This paper reports the pre-installation visits, when the RWE Smarthome ${ }^{\mathrm{TM}}$ system and Z-Wave smart plugs were presented to the households. These visits took place after the first phase (when background monitoring equipment was installed) and closely preceded the second phase (when the SHTs were installed). The participants' first contact with the SHTs (which users would actually control) was used as an opportunity to investigate issues surrounding the introduction these devices into participants' homes. After presenting and briefly demonstrating how the devices work, semi-structured interviews were conducted, and when possible, all family members took part in the discussion. From the 20 participant households, 16 were interviewed in this stage of the project (Table 1). The final installation process was scheduled for one

\footnotetext{
${ }^{1}$ https://www.rwe-smarthome.de/web/cms/en/448330/smarthome/

${ }^{2} \mathrm{http}: / /$ getvera.com/

${ }^{3}$ http://www.currentcost.com/

${ }^{4}$ https://www.hivehome.com/
} 
week after this visit. Four households (of the 16) were interviewed on the same day of the actual installation due to schedule conflicts.

The topics of the interviews focused on decisions about which of the available equipment they want to use, where to install equipment in the home, how to position those, concerns related to aesthetics, damages to the property and so on. The audio data from these interviews has been transcribed and thematically analysed to provide insights into households' decision making process, expectations and perceived barriers to the introduction of the technology. We also asked if they looked for information elsewhere, how involved they were with these decisions, and how happy they were with changes during the process. All recordings were imported to NVivo, to allow coding of each statement into themes and to provide a better understanding of the qualitative data.

Table 1 - Households' demographics

\begin{tabular}{|c|c|c|c|}
\hline \multirow{2}{*}{ House code } & \multirow{2}{*}{$\begin{array}{c}\text { Number of } \\
\text { residents }\end{array}$} & Male & Female \\
\cline { 3 - 4 } & 2 & 65 & 63 \\
\hline 1 & 4 & 35 & 37 \\
\hline 2 & 2 & 64 & 69 \\
\hline 3 & 2 & 64 & 65 \\
\hline 4 & 4 & 51 & 47 \\
\hline 5 & 2 & 54 & 59 \\
\hline 6 & 4 & 44 & 41 \\
\hline 7 & 2 & 79 & 72 \\
\hline 8 & 4 & 43 & 41 \\
\hline 10 & 1 & & 71 \\
\hline 11 & 1 & & 45 \\
\hline 15 & 3 & 62 & 59 \\
\hline 17 & 2 & 73 & 71 \\
\hline 18 & 4 & 43 & 48 \\
\hline 19 & 2 or 3 & 58 & 55 \\
\hline 20 & 4 & 32 & 43 \\
\hline 21 & & & \\
\hline
\end{tabular}

\section{RESULTS}

Participants mentioned a wide range of issues surrounding the introduction of the smart kit. To guide the qualitative analysis, an organizing framework for research on smart homes and their users was used [55]. Responses were coded into 9 different categories involving the reasons for adopting smart homes, who are the users, and the challenges for realising the smart home. Figure 1 shows the coding frequency on each aspect of the framework, with breakdown of themes contained in each box. We present below an overview of these themes captured from the interviews as categorized by the organizing framework.

\section{A. Grand 'narratives' of the smart home}

The first aspect is related to the grand 'narratives' of the smart home, comprising the reasons why people adopt these technologies. When prompted via the semi-structured interview, or when being presented with the devices, the larger number of responses involved the functional aspect of smart homes. Participants envision several aspects of their domestic life that can benefit from the introduction of smart technology. Security and safety were often mentioned, either to monitor intruders or occupants via the motion sensors and door and window contacts. Having another smoke detector and alarm was also appreciated.

The convenience of controlling temperature in rooms for different occasions using wall-mounted switches, and remote controls for the heating system were also frequently stated. The female adult participant from house 17 (H17-F) explains her expectations of less effort allowed by the controls: "This on/off switch looks good to me! (laughs) Just press a button and that's done nice and easy, yeah!" The male adult in house 10 (H10-M) illustrates the usefulness of zonal control: "presumably it's mainly about keeping the temperature in rooms comfortable".

Substantially less mentions involved the instrumental aspect of SHTs. The system can help households achieve reductions, as H7-M describes: "Maybe we'll save some energy, save some money on energy possibly". H3-M adds the need to make energy visible: "What I'm hoping to see is how we are actually behaving in terms of the house and the energy we are using in the house, the patterns of the day, of the week, of the month, of the season".

Socio-technical motivations were also mentioned during the visits. Some participants wanted to be up to date with new technology, learn and engage with new technologies, as H19-F describes: "So it's interesting to be sort of in at the start of this stuff being used". H10-M mentions the integration of technology as a co-evolution and incremental adoption of 'stuff' [47] into their house:

We've got a second router which Google or Streetwise or whatever they're called... which is 'daisy chained' I think he called it, into one of the other routers. And then we've got the Virgin router where you know... (laughs) So we don't really need all of those, I don't quite know how we've ended up with so many.

Often participants expected more features than possible with the systems being introduced, such as advanced security with CCTV or integration with existing equipment, for example automatic curtains, non-programmable dishwasher or washing machines, and ceiling lights.

\section{B. Users and the use of the smart home}

The second category in the research framework identify who uses the smart home and how. It aggregated the classification of participants, how they would use the smart home and how their homes are characterised. We observed five households demonstrating advanced rational use of energy. Participants were explaining their current habits, their recently updated appliances or energy management techniques. H8-F explains how she makes good use of the cheaper overnight tariff:

I mean now, because it's half past 8 cut off, you know we're up at 6 in the morning, I can have some cakes made in that time, you know. If I worked it out the night before and weighed the ingredients out, when I get, come downstairs in the 
morning, all I've got to do is switch on the mixer, turn the oven on and while I'm having a shower, the cakes are cooking! (laughs)

This level of commitment to cheap electricity is remarkable given that it can be difficult to adapt everyday routines to fit in with flexible tariffs [44]. Householders also demonstrated a need for control, when wanting to have access to raw data or planning to use patterns of room occupation. Participants mentioned performing improvements to the house such as redecorating and DIY or incorporating different technologies, usually installing it themselves.

H6-M wanted to use the smart home controls to improve the heating system to modern standards:

That's the motivation for doing this, it's to get a heating system that is actually realistic in a modern world. You know, you can control rooms and you could use external triggers etcetera. So that's where I want to be, I want to move from a system that is in my view totally antiquated.

The information provided by SHTs can motivate new patterns of behaviours as a way to promote energy saving among occupants [57]. H3-M describes how he could use data coming from the installed devices:

I expect is that once, once this programme is stable, a picture will emerge that will be contrasted with the baseline that has been set over the months before, that is going to show [female] and me where we should change our lifestyle or habits to improve our energy efficiency.

Further use of data provided by the smart home system was proposed by H21-F. Although not related to energy efficiency retrofits, she explains how occupancy data can inform planed works: "We're looking at extending the house, so it would be quite interesting, where we do spend more of our time and

Grand 'narratives' of the smart home

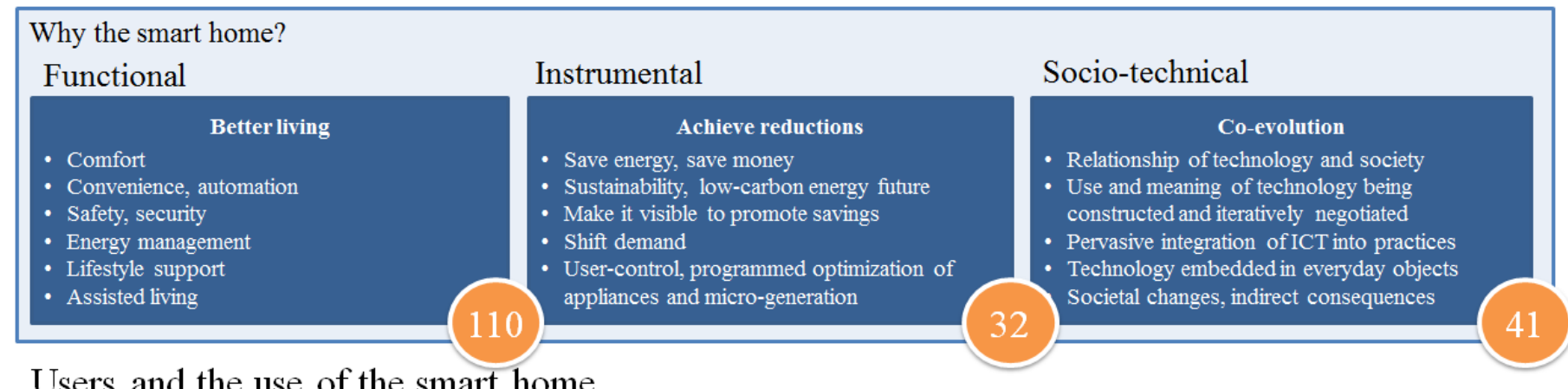

Users and the use of the smart home

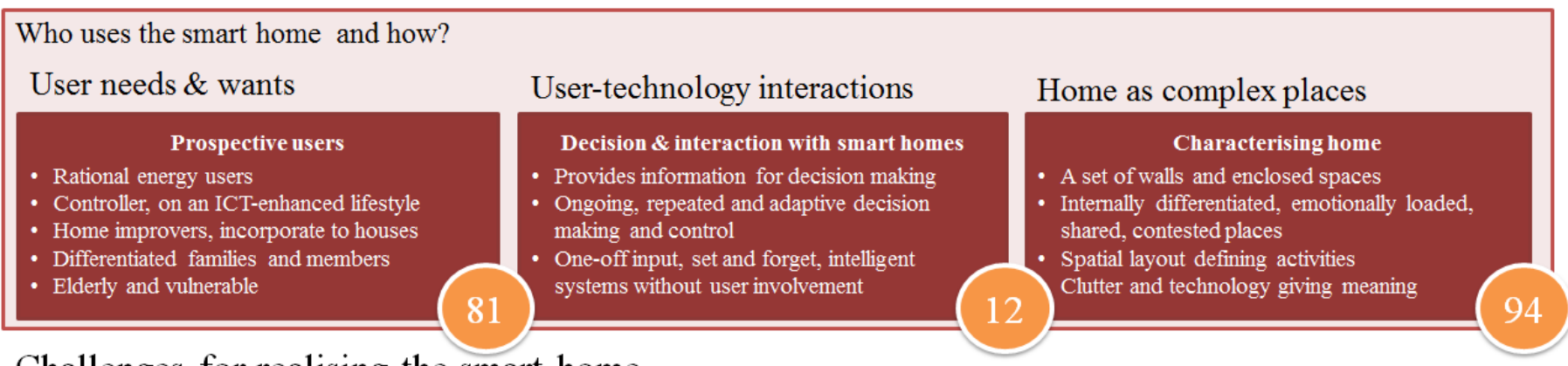

\section{Challenges for realising the smart home}

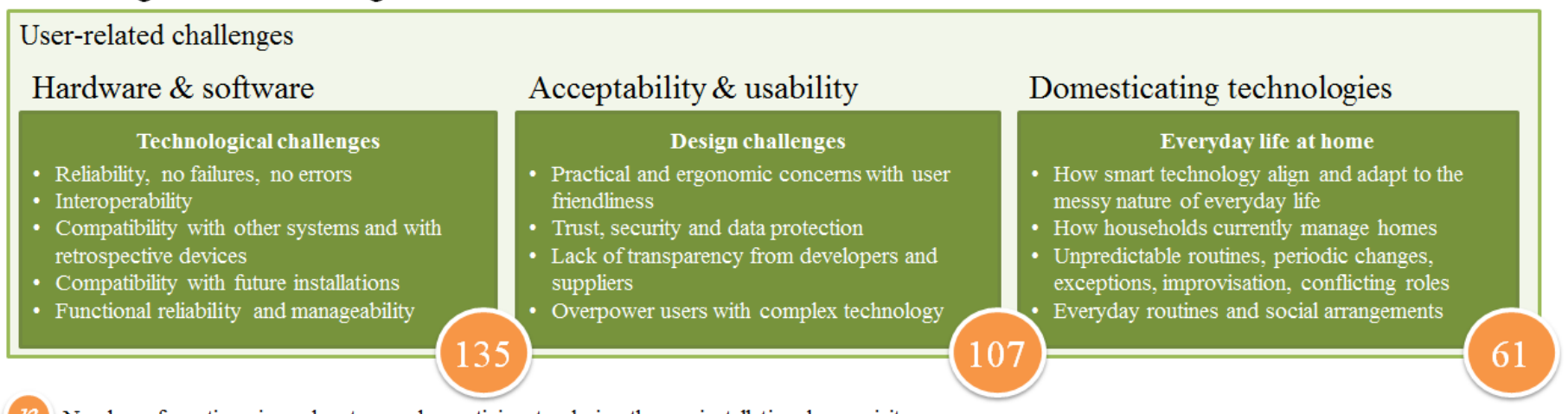

Number of mentions in each category, by participants, during the pre-installation home visits

Figure 1 - Organizing framework for research on smart home and their users, adapted from [55] with coding frequency 
whether or not what we're planning is the right sort of thing".

During the interviews participants defined the complexity of their homes, usually more than a set of walls and enclosed spaces. H4-F's description of their house presents challenges to thermal management: "This is solid wall, high ceilings, the extension is cavity wall, insulated, lower ceilings. [...] Two things going on at once, yeah". This setting would make it difficult for algorithms to predict the building performance since simulations are generally done in standard houses [4], but would benefit from zonal controls provided by SHT. Participants' homes were also emotionally loaded and contested places. The introduction of sensors, controls and central units affects the aesthetics of the house in different levels for different households. H6-M illustrates:

I was thinking, how on earth am I going to hide the cables? Am I going to need to mount it on the wall, and how? Well the biggest practicality is, how do I get the Ethernet cable from this box to the Vera box and make it look alright?

This concern is in clear contrast to other participants who laughed about the 'spaghetti of wires' they have, the cobwebs and how the spiders must be happy 'in that corner where the router is'.

\section{Challenges for realising the smart home}

Participants frequently mentioned issues relating to the challenges for realising the smart home, for example technological aspects of hardware and software. Participants demonstrated also concerns with errors, failures, and the amount of batteries being used by the devices. Some participants were not equipped to use the smart home to its full extent, and the introduction of smart controls seemed problematic compared to current arrangements. When told that she will be able to control the system via a smartphone, H11-F replied:

I'm not going to get a smartphone unless somebody tells me... you know, for some reason I have to, I do not want one! So, and I'm not going to go on my computer to change a radiator valve because I'd just go into the room to change it, if I ever did!

Another user-related challenge involves the acceptability and usability of the systems. Participants were afraid that it may be too complicated and difficult to understand, control and use. The concept of 'learning curve' was mentioned a few times. This is a recurrent challenge on smart home research [25]. Some participants also mentioned that the devices are not very aesthetically pleasant, too big or don't match the decor. Concerns with trust, security and data protection were also mentioned, as H19-F illustrates:

If it just detects one person in the house coming in regularly at this time, that could be a security issue. I mean, [male]'s away a lot, so I'm here on my own and it is quite dark and quiet and... (laughs) you know, it's those kind of things that you... (laughs) I mean... How secure is the data?

Our interviews pictured users' lives as being complex and inserted in messy environments, with unpredictable routines, exceptions and periodic changes. Technology is often pushed into people's homes without a comprehensive understanding of user needs [35]. Some households doubted how SHT matches their everyday life, practices and the way they manage their homes. People normally already have arrangements to control temperatures and appliances. Some participants see that technology is not needed for certain tasks, or may require a change in practices to accommodate and domesticate the new technology. H21-M illustrates: "I think it will take a bit of getting used to because it's a different way of how we already run and do the heating and those sorts of things". Household 7 indicated that SHTs may not be of much use for their current lifestyles:

Female: It's always worked really well, the boiler's just programmed to come on at certain times with the heating, and we just leave it at that and forget about it all winter don't we?

Male: Yeah... you can go, oh I've forgotten to turn the heating off, I can turn it off, I don't need to leave it on, but ... I think it's going to be probably quite ... limited because we're on a schedule!

Conflicting roles between who wants to manage the heating system efficiently and who wants to get on with the domestic tasks were illustrated by the couple in house 02 :

Male: - So I can stop [female] from drying the washing in the house with the windows open and the radiators on using those [window contact sensors], can't I? Because it will turn the radiator off when there's a window open.

Female: - As long as you're not bothered about not having any dry clothes, clean dry clothes, that's fine!

\section{DISCUSSION}

The reduction of carbon emissions in the domestic sector requires more commitment than what is currently in place, and efforts should combine behavior change and infrastructure improvements to meet the challenging targets. Retrofit measures can be implemented to bring current homes to tough standards of efficiency and thermal performance and reduce space heating energy demand. SHTs have the potential to improve control and inform homeowners about the performance of their houses, and therefore indicate possible changes in behavior or infrastructure upgrades that could bring about energy efficiency.

Nowadays households are experiencing an intensification of smartness in the domestic environments. More systems are being pushed into homes by technological developments, government regulations and the wide availability of SHT offthe-shelf. These systems are beginning to penetrate beyond an audience of wealthy or tech-savvy homeowners, but have yet to be widely adopted [42]. Before we are able to see any broad implementation, more research is needed to understand issues surrounding the installation process.

The analysis of interviews described in this paper indicates that households tapped a myriad of factors related to both enablers and barriers to the adoption of SHTs. Participants' expectations include the benefits already stablished by previous research and industry, such as functional (comfort, convenience, security), instrumental (savings, sustainability, feedback) and socio-technical (keep on with technology). 
However, a large number of challenges were mentioned by participants, even before they started using the technology.

Our participants described diverse routines in place in activities such as laundry, cooking or heating. These activities were determined by a range of factors including the available infrastructure, their competencies and the perceived efficient method for achieving their objectives (e.g. drying clothes with the windows open). Higher level 'systems of provision' such as the supplier's tariff also influenced activities (e.g. baking cakes at 6 in the morning). Frequently, heating systems are used in a 'set and forget' fashion, and the introduction of smart controls may disrupt this convenience and comfort. Even when using modern smart thermostats, the novelty wears off and consequently fine-tuning schedules for energy efficiency does not last long [58]. The energy intense activities at home are embedded in practices and therefore need to be better understood, and it presents challenges to the introduction of SHTs if it requires changes in these practices [48].

One frequent issue raised by participants was the perceived difficulty of use. People are familiar to frustrations caused by technology, and a new system in the home was approached with care. Our participants ranged from tech-savvy to technophobes. Some were in fact unsure of the suitability of the technology into their environments. They showed concerns with a possible over-powering and complex technology replacing simple tasks like switching off radiator valves. As Mennicken and Huang put it, "it's not smart if I can do it better" [42]. People are often negatively aware of the difficulties surrounding new technologies, and our results support the challenges that Brush et al. indicated about unreliability and complexity [9].

One of the advantages of using SHTs as part of a decision making support tool is that it can empower homeowners to come up with their own solutions to improve energy efficiency. We observed that some of our participants' houses had been through a number of modifications and extensions over the years. We also noticed complex levels of integration between the built environment and existing technologies [47], requiring retrospective compatibility and possibility of incremental smartness. It is also important to "respect existing technological arrangements in the home and make new installations fit in with them" [51].

The uniqueness of our participant's homes aligns with previous research demonstrating that "[m]any UK homes have peculiarities and physical constraints which do not enable them to be simply retrofitted with standard solutions" [30]. Our sample houses seemed to be also emotionally loaded and contested spaces, with participants concerning about the possible physical damage or compromised aesthetics caused by the introduction of SHTs. Homeowners are best suited to discover the unique potential of their properties, considering the physical and emotional aspects to negotiate the feasible efficiency measures.

Managing and programming SHTs may conflict with how families operate. Our interviews took place at our volunteer's homes, with all members of the family when possible. Even though we are treating households as a unit, the counts of mentions refer to each participant. Further data analysis can take place to identify better the internal discrepancies or agreements, and how it affects the way people manage and control SHTs. It was shown that "[r]esponsibility or ownership of tasks in a family is rarely clearly-defined" [17].

SHTs have the potential to generate useful knowledge and present it back to the user in a meaningful way. Through intelligent agents and cloud computer, it can recognize patterns, offer predictions and trends and sometimes even take action on users' behalf [12]. It indicates that agents can be useful to manage the energy consumption and promote savings. However, a better understanding of users in context is needed to convince them retrofitting their homes.

Modern building techniques and materials can guarantee that new homes are efficient and comply with building recommendations [39]. When building new houses it is possible to incorporate SHTs custom designed from the start [25]. However, with the predominantly old housing stock in the UK and its slow renewal, there's a triple challenge: first, it is necessary to find ways to fit SHT into existing homes [3]. Then, to define which retrofit measures would be more adequate. Finally, proceed with the retrofit to improve energy efficiency. We believe that SHTs can provide the information to guide these improvements, once adopted by households. Further phases of this research will involve the development of decision support systems to for providing retrofit advice using data from SHTs.

Participants of our study didn't have to pay any of the costs involved with the installation of SHTs. For that reason, financial barriers were not mentioned as a challenge for adoption. Initial costs and payback periods are a concern among those who have to fund their own systems [9]. Often the installation process requires upgrades to existing hardware, such as incompatible or defective radiator valves. Other than the devices and systems themselves, costs involving labor and parts surely create further challenges for broader adoption of SHTs.

\section{CONCLUSION}

This study contributes to the existing knowledge of domestic energy use and users in an attempt to understand better the challenge of sustainable consumption, human behaviour and lifestyle [48]. This paper presented results from interviews with 16 households as part of the REFIT project. In the context of this study, thematic analysis indicates that the challenges are stronger and more frequent than the motivations for realising the smart home. Nevertheless, it presents opportunities for both industry and academia to understand that there is a tendency to focus on the technical aspects of smart homes. It is necessary to dedicate more effort to understand users, scenarios and contexts. Design research methods and social sciences research can be incorporated into the engineering and technical sciences to foster the development of SHTs and therefore improve its acceptance. With a truly interdisciplinary development we can improve the chances of a wider adoption of these technologies and consequently realise the benefits of SHTs to improve homes, lives and promote sustainable energy consumption. 


\section{ACKNOWLEDGEMENTS}

This work has been carried out as part of the REFIT project ('Personalised Retrofit Decision Support Tools for UK Homes using Smart Home Technology', £1.5m, Grant Reference $\mathrm{EP} / \mathrm{K} 002457 / 1)$. REFIT is a consortium of three universities Loughborough, Strathclyde and East Anglia - and ten industry stakeholders funded by the Engineering and Physical Sciences Research Council (EPSRC) under the Transforming Energy Demand in Buildings through Digital Innovation (BuildTEDDI) funding programme. For more information see: www.epsrc.ac.uk and www.refitsmarthomes.org.

\section{REFERENCES}

[1] ANDERSON, W. AND WHITE, V. 2009. Exploring consumer preferences for home energy display functionality. http://www.cse.org.uk/downloads/reports-and-publications/behaviourchange/consumer_preferences for home energy display.pdf.

[2] BALTA-OZKAN, N., DAVIDSON, R., BICKET, M. AND WHITMARSH, L. 2013. Social barriers to the adoption of smart homes. Energy Policy 63, 363-374

[3] BALTA-OZKAN, N., DAVIDSON, R., BICKET, M. AND

WHITMARSH, L. 2013. The development of smart homes market in the UK. Energy 60, 361-372.

[4] BEIZAEE, A., ALLINSON, D., LOMAS, K.J., FODA, E. AND LOVEDAY, D.L. 2015. Measuring the potential of zonal space heating controls to reduce energy use in UK homes: The case of un-furbished 1930s dwellings. Energy and Buildings 92, 29-44.

[5] BERKHOUT, P.H.G., MUSKENS, J.C. AND W. VELTHUIJSEN, J. 2000. Defining the rebound effect. Energy Policy 28, 425-432.

[6] BLEVIS, E. 2007. Sustainable interaction design: invention \& disposal, renewal \& reuse. In Proceedings of the SIGCHI conference on Human factors in computing systems, ACM, 503-512.

[7] BOARDMAN, B. 2007. Examining the carbon agenda via the $40 \%$ House scenario. Building Research \& Information 35, 363-378.

[8] BOOTH, A.T. AND CHOUDHARY, R. 2013. Decision making under uncertainty in the retrofit analysis of the UK housing stock: Implications for the Green Deal. Energy and Buildings 64, 292-308.

[9] BRUSH, A., LEE, B., MAHAJAN, R., AGARWAL, S., SAROIU, S AND DIXON, C. 2011. Home automation in the wild: challenges and opportunities. In Proceedings of the SIGCHI Conference on Human Factors in Computing Systems, ACM, 2115-2124.

[10] BUCHANAN, K., RUSSO, R. AND ANDERSON, B. 2015. The question of energy reduction: The problem (s) with feedback. Energy Policy $77,89-96$.

[11] BUCHANAN, K., RUSSO, R. AND ANDERSON, B. 2014. Feeding back about eco-feedback: How do consumers use and respond to energy monitors? Energy Policy.

[12] COOK, D.J. 2012. How smart is your home? Science (New York, N.Y.) $335,1579-1581$.

[13] CRAWFORD, K., JOHNSON, C., DAVIES, F. AND JOO, S. 2014. Demolition or Refurbishment of Social Housing? A review of the evidence. http://www.engineering.ucl.ac.uk/engineering-exchange/files/2014/10/ReportRefurbishment-Demolition-Social-Housing.pdf.

[14] CROSBIE, T. AND BAKER, K. 2010. Energy-efficiency interventions in housing: learning from the inhabitants. Building Research \& Information 38 , 70-79.

[15] DARBY, S. 2001. Making it obvious: designing feedback into energy consumption. In 2nd International Conference on Energy Efficiency in Household Appliances and Lighting, Naples, Italy, September 27-29, 2000 Italian Association of Energy Economists, EC-SAVE programme, 1-11.
[16] DARBY, S. 2006. The effectiveness of feedback on energy consumption - A Review for DEFRA of the Literature on Metering, Billing and direct Displays. 2009

[17] DAVIDOFF, S., LEE, M.K., YIU, C., ZIMMERMAN, J. AND DEY, A.K. 2006. Principles of smart home control. In UbiComp 2006: Ubiquitous Computing, Springer, 19-34.

[18] DECC. 2009. Annual tables: Digest of UK Energy Statistics - DUKES. Accessed: 11 December 2012,

http://www.decc.gov.uk/en/content/cms/statistics/publications/dukes/dukes.as px.

[19] DECC. 2011. Green Deal and Energy Company Obligation Consultation Document. Accessed: 03 March 2015 ,

http://www.decc.gov.uk/assets/decc/11/consultation/green-deal/3607-greendeal-energy-company-ob-cons.pdf.

[20] DECC. 2011. Smart Metering Implementation Programme: Response to Prospectus Consultation. Accessed: 21 March 2015, https://www.gov.uk/government/consultations/delivering-smart-meters-tohomes-and-businesses.

[21] DECC. 2015. Smart Meters, Smart Data, Smart Growth. Accessed: 21 April 2015, https://www.gov.uk/government/publications/smart-meters-smartdata-smart-growth

[22] DESJARDINS, A., WAKKARY, R. AND ODOM, W. 2015. Investigating Genres and Perspectives in HCI Research on the Home. In $\mathrm{CHI}$ 2015 - The ACM CHI Conference on Human Factors in Computing Systems (accepted for publication), Seoul, Republic of Korea, April 18 - 23,

[23] DIMITRIOU, V., FIRTH, S.K., HASSAN, T.M., KANE, T. AND FOUCHAL, F. 2014. Developing suitable thermal models for domestic buildings with Smart Home equipment. In Building Simulation and Optimization Conference, UCL, London, UK, 23-24 June 2014, The Bartlett, UCL Faculty of the Built Environment Institute for Environmental Design and Engineering (@ IBPSA-England), 1-8.

[24] DISALVO, C., SENGERS, P. AND BRYNJARSDÓTTIR, H. 2010. Mapping the landscape of sustainable HCI. In Proceedings of the 28th international conference on Human factors in computing systems, April 1015, ACM, 1975-1984

[25] EDWARDS, W.K. AND GRINTER, R.E. 2001. At home with ubiquitous computing: seven challenges. In Ubicomp 2001: Ubiquitous Computing, Springer, 256-272.

[26] ELAFOUDI, G., STANKOVIC, L. AND STANKOVIC, V. 2014. Power disaggregation of domestic smart meter readings using dynamic time warping. In Communications, Control and Signal Processing (ISCCSP), 2014 6th International Symposium on, IEEE, 36-39.

[27] EUROPEAN COMMISSION. 2015. 2030 framework for climate and energy policies. 2015 ,

http://ec.europa.eu/clima/policies/international/negotiations/future/index_en.ht m.

[28] FIRTH, S.K., FOUCHAL, F., KANE, T., DIMITRIOU, V. AND HASSAN, T.M. 2013. Decision support systems for domestic retrofit provision using smart home data streams. In CIB W78 30th International Conference, Beijing, China, 9-12 October, CIB, 1-10.

[29] FISCHER, C. 2008. Feedback on household electricity consumption: a tool for saving energy? Energy Efficiency 1, 79-104

[30] GALVIN, R. AND SUNIKKA-BLANK, M. 2014. The UK homeownerretrofitter as an innovator in a socio-technical system. Energy Policy 74, 655662 .

[31] GELLER, H., HARRINGTON, P., ROSENFELD, A.H., TANISHIMA, S. AND UNANDER, F. 2006. Polices for increasing energy efficiency: Thirty years of experience in OECD countries. Energy Policy 34, 556-573.

[32] GILL, Z., TIERNEY, M.J., PEGG, I.M. AND ALLAN, N. 2010. Lowenergy dwellings: the contribution of behaviours to actual performance. Building Research \& Information 38, 491-508.

[33] GOODMAN, E. 2009. Three environmental discourses in humancomputer interaction. In Proceedings of the 27th international conference 
extended abstracts on Human factors in computing systems, ACM New York, NY, USA, 2535-2544.

[34] GREENING, L.A., GREENE, D.L. AND DIFIGLIO, C. 2000. Energy efficiency and consumption - the rebound effect - a survey. Energy Policy 28, 389-401.

[35] HAINES, V., MITCHELL, V., COOPER, C. AND MAGUIRE, M. 2007. Probing user values in the home environment within a technology driven Smart Home project. Personal and Ubiquitous Computing 11, 349-359.

[36] HARGREAVES, T, \& WILSON, C. 2013. Who uses smart home technologies? Representations of users by the smart home industry. In European Council for an Energy Efficient Economy (ECEEE) Summer Study, Toulon/Hyères, France, 3rd-8th June 2013., 1769-1780.

[37] HAZAS, M., FRIDAY, A. AND SCOTT, J. 2011. Look back before leaping forward: Four decades of domestic energy inquiry. IEEE pervasive Computing 10, 13-19.

[38] HILTY, L.M. AND LOHMANN, W. 2013. An annotated bibliography of conceptual frameworks in ICT for sustainability. In Proceedings of the First International Conference on Information and Communication Technologies for Sustainability (ICT4S), ETH Zurich, February 14-16, 288-300.

[39] HM GOVERNMENT. 2011. Carbon Plan - Delivering our low carbon future. Accessed 15 March 2015,

https://www.gov.uk/government/uploads/system/uploads/attachment_data/file 147613/3702-the-carbon-plan-delivering-our-low-carbon-future.pdf.

[40] HUANG, E.M. 2011. Building outwards from sustainable HCI. interactions $18,14-17$.

[41] MALLABAND, B., HAINES, V. AND MITCHELL, V. 2012. Barriers to domestic retrofit-learning from past home improvement experiences.

[42] MENNICKEN, S. AND HUANG, E.M. 2012. Hacking the natural habitat: an in-the-wild study of smart homes, their development, and the people who live in them. In Pervasive Computing, Springer, 143-160.

[43] NILSSON, A., BERGSTAD, C.J., THUVANDER, L., ANDERSSON, D., ANDERSSON, K. AND MEILING, P. 2014. Effects of continuous feedback on households' electricity consumption: Potentials and barriers Applied Energy 122, 17-23.

[44] PAETZ, A., DÜTSCHKE, E. AND FICHTNER, W. 2012. Smart homes as a means to sustainable energy consumption: A study of consumer perceptions. Journal of consumer policy 35, 23-41.

[45] PETTIFOR, H., WILSON, C. AND CHRYSSOCHOIDIS, G. 2015. The appeal of the green deal: Empirical evidence for the influence of energy efficiency policy on renovating homeowners. Energy Policy 79, 161-176.

[46] POWER, A. 2010. Housing and sustainability: demolition or refurbishment? Proceedings of the ICE-Urban Design and Planning 163, 205216.

[47] RODDEN, T. AND BENFORD, S. 2003. The evolution of buildings and implications for the design of ubiquitous domestic environments. In
Proceedings of the SIGCHI conference on Human factors in computing systems, ACM, 9-16.

[48] SHOVE, E. 2005. Changing human behaviour and lifestyle: a challenge for sustainable consumption? In The Ecological Economics of Sustainable Consumption, Northampton, MA, I. ROPKE \& L. REISCH, Ed. Edward Elgar, 111-132.

[49] SILBERMAN, M. AND TOMLINSON, B. 2010. Toward an ecological sensibility: tools for evaluating sustainable HCI. In Proceedings of the 28th of the international conference extended abstracts on Human factors in computing systems, ACM, 3469-3474.

[50] STEG, L. AND VLEK, C. 2009. Encouraging pro-environmental behaviour: An integrative review and research agenda. Journal of Environmental Psychology 29, 309-317.

[51] TOLMIE, P., CRABTREE, A., EGGLESTONE, S., HUMBLE, J., GREENHALGH, C. AND RODDEN, T. 2010. Digital plumbing: the mundane work of deploying UbiComp in the home. Personal and Ubiquitous Computing 14, 181-196.

[52] WEEKS, C., DELALONDE, C. AND PREIST, C. 2014. Power law of engagement: Transferring disengaged householders into retrofitting energy savers. In Proceedings of the Second International Conference on Information and Communication Technologies for Sustainability (ICT4S-14), Stockholm, August 24-27, Atlantis Press.

[53] WILSON, C., CRANE, L. AND CHRYSSOCHOIDIS, G. 2013. Why do people decide to renovate their homes to improve energy efficiency? Tyndall Centre for Climate Change Research, Norwich, UK, working paper.

[54] WILSON, C., CRANE, L. AND CHRYSSOCHOIDIS, G. 2015. Why do homeowners renovate energy efficiently? Contrasting perspectives and implications for policy. Energy Research \& Social Science 7, 12-22.

[55] WILSON, C., HARGREAVES, T. AND HAUXWELL-BALDWIN, R. 2014. Smart homes and their users: a systematic analysis and key challenges Personal and Ubiquitous Computing 1-14.

[56] WILSON, G.T., BHAMRA, T. AND LILLEY, D. 2015. The considerations and limitations of feedback as a strategy for behaviour change. International Journal of Sustainable Engineering 8, 186-195.

[57] WOOD, G. AND NEWBOROUGH, M. 2003. Dynamic energyconsumption indicators for domestic appliances: environment, behaviour and design. Energy \& Buildings 35, 821-841.

[58] YANG, R., NEWMAN, M.W. AND FORLIZZI, J. 2014. Making sustainability sustainable: Challenges in the design of eco-interaction technologies. In Proceedings of the 32nd annual ACM conference on Human factors in computing systems, ACM, 823-832.

[59] YUN, T.J. 2009. Investigating the impact of a minimalist in-home energy consumption display. In Proceedings of the 27th international conference extended abstracts on Human factors in computing systems, April 4-9, 2009 ACM, 4417-4422. 